\title{
Characteristics of Avian Influenza H9N2 Virus Isolated from Humans and its Seroprevalence Among Occupationally Exposed Populations in China
}

\section{Jie Dong}

National Institute for Viral Disease Control and Prevention

Hong Bo

National Institute for Viral Disease Control and Prevention

Libo Dong

National Institute for Viral Disease Control and Prevention

Ye Zhang

National Institute for Viral Disease Control and Prevention

\section{Weijuan Huang}

National Institute for Viral Disease Control and Prevention

\section{Shumei Zou}

National Institute for Viral Disease Control and Prevention

Xiyan Li

National Institute for Viral Disease Control and Prevention

Lei Yang

National Institute for Viral Disease Control and Prevention

Xiaoxu Zeng

National Institute for Viral Disease Control and Prevention

Jia Liu

National Institute for Viral Disease Control and Prevention

Tao Chen

National Institute for Viral Disease Control and Prevention

Yuelong Shu

National Institute for Viral Disease Control and Prevention

Dayan Wang ( $\nabla$ wangdayan@ivdc.chinacdc.cn )

National Institute for Viral Disease Control and Prevention

\section{Research Article}

Keywords: Influenza, H9N2 subtype, Human infection, Receptor binding, Neuraminidase inhibitor, Seroprevalence

Posted Date: June 9th, 2021

DOI: https://doi.org/10.21203/rs.3.rs-568946/v1

License: (c) (i) This work is licensed under a Creative Commons Attribution 4.0 International License. Read Full License 


\section{Abstract}

Background: The first human-infected H9N2 influenza case can be traced back to 1998. Although the H9N2 influenza virus has low pathogenicity in animals, it donated partial or whole cassettes of internal genes to reassort novel viruses, such as H7N9, H10N8 and H5N6 viruses, that caused human infections with high fatality. Since 2013, sporadic but increasingly frequent human cases caused by H9N2 influenza virus have been confirmed globally, and most of them were from China.

Methods: Information on human infections with H9N2 influenza virus was collected. Viral molecular determinants were determined by deep sequencing, and phylogenetic analysis was performed using MEGA 6.06. Antigenic analysis was performed by a hemagglutination inhibition (HI) assay. Receptor binding preference analysis was conducted based on a solid-phase binding assay with synthetic sialylglycopolymers. Antiviral susceptibility was determined by a fluorescence-based neuraminidase (NA) inhibition assay. Serological study of occupationally exposed populations was performed by $\mathrm{HI}$ assay screening and confirmed by microneutralization assay.

Results: From 2013 to 2018, 33 human H9N2cases were reported in China, among them 75.7\% were children under 10 years old .The 22 viruses were isolated and concentrated in the Y280/G9 lineage of the HA and NA genes. All human H9N2 viruses belonged to the Y280/G9 antigenic lineage, presented a humanlike receptor binding preference and remained susceptible to NA inhibitors, but most demonstrated resistance to M2 inhibitors. The seroprevalence of occupationally exposed populations was $2.15 \%, 3.17 \%, 2.93 \%$ and $1.54 \%$ from 2015 to 2018 , respectively. A significant difference in seroprevalence was shown between provinces with human cases (3.66\%) and provinces without human cases $(2.18 \%)$.

Conclusions: The continuous antigenic drift and human-like receptor binding preference of the H9N2 virus enable it to have a high risk of causing human infections. The status of the seropositivity in occupationally exposed populations implies a substantial threat to public health. Research on human infection with H9N2 influenza virus should be strengthened to monitor the emergence of sustainable human-to-human transmission and the possibility of an endemic or a pandemic related to it.

\section{Background}

The earliest published avian influenza outbreak caused by H9N2 influenza virus in China can be traced to 1992 [1]. Since 1998, H9N2 had been a predominating subtype of avian influenza virus affecting the poultry industry through the beginning of the 21 st century. Even in current times, H9N2 avian influenza is still endemic, imposing an animal health threat and causing economic losses.

Apart from its impact on animal health, the public health threat to humans is also critical. As documented in the first human cases infected with avian influenza H9N2 virus, which were reported by Dr. Guo's team in 1998 in China, the H9N2 influenza virus could traverse the species barrier and infect humans directly. Next, five virus strains were isolated from respiratory tract specimens of outpatients and inpatients in the southern region of China [2]. Then, 2 children in Hong Kong [3] and 1 infant from southern China were reported infected in 1999 [4]. The second human H9N2 infection in Hong Kong was reported in December 2003. However, recently, sporadic human infections of H9N2 influenza virus have been confirmed and reported to the World Health Organization (WHO); these infections were from China, Bangladesh, Egypt, Oman and Pakistan [5], and the majority was from China.

The strong ability of influenza H9N2 virus adaptation and evolution in poultry populations makes it a great threat to public health due to its supporting role in the emergence of novel lethal influenza viruses, such as H7N9, H10N8 and H5N6 [6-8]. Enhanced surveillance of human infection with avian influenza has occurred, including for the abovementioned novel influenza and influenza H9N2 itself.

Systematic studies on the genetic and antigenic profiles, receptor binding properties, and antiviral susceptibility of H9N2 viruses isolated from humans and the seroprevalence of the H9N2 virus in occupationally exposed populations are essential for global risk assessment. This study is the first general analysis of all available human-isolated H9N2 influenza viruses in China till to 2018 and the serological study among occupationally exposed populations nationwide in China.

\section{Methods}

\section{Viruses and cells}

The H9N2 viruses used in this study were isolated from humans and were proliferated in specific pathogen-free (SPF) embryonated chicken eggs. MadinDarby canine kidney (MDCK) cells were used for virus titration. MDCK cells were cultured in DMEM with $5 \%$ fetal bovine serum (FBS).

\section{Hemagglutination assay with different types of erythrocytes}

A $1 \%$ erythrocyte suspension was prepared with chicken, turkey, guinea pig and horse red blood cells (RBCs). The HA titers were determined as described previously [9].

\section{Gene sequencing and phylogenetic analysis}

A MagMAX ${ }^{\text {TM }}$ CORE Nucleic Acid Purification Kit was used to extract viral RNA, which was amplified using an Invitrogen Superscript One-step RT-PCR Platinum Taq HiFi Kit. The primers and probes used were previously described. A Qiagen MinElute Reaction Cleaning Kit was used to purify the PCR products. NGS (next-generation sequencing) sample preparation processed $1 \mathrm{ng}$ of purified DNA product with an Illumina Nextera XT DNA sample preparation kit (96 samples). Sequencing was performed using a MiSeq v2 kit as previously described [10]. The full genome sequence was assembled by the CLC platform. 
Homology analysis of nucleic acids and amino acids was performed on the NCBI website with BLAST. Phylogenetic analysis was performed on MEGA 6.06 using the Maximum Likelihood method. The reliability of the tree topology was assessed by bootstrapping with 1000 replications.

\section{Receptor binding preference analysis}

A solid-phase binding assay was used as described previously [11]. Synthetic sialylglycopolymers, including 3'-SLN, 6'-SLN, 3'-SL, and 6'-SL

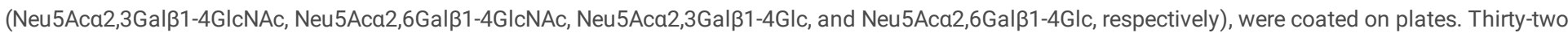
hemagglutination units (HAUs) of each virus were added to each well. An ELISA was then used. The primary antibody was a universal monoclonal antibody

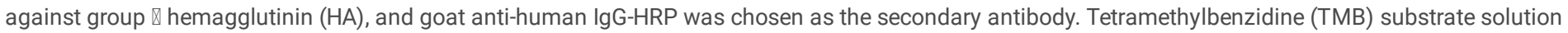
(BD Biosciences) was used to visualize the results. The optical density was read at $450 / 630 \mathrm{~nm}$.

\section{Antigenic analysis}

$\mathrm{A} \mathrm{HI}$ assay was performed to indicate the antigenicity difference. The paired viruses and relevant polyclonal ferret antisera were used as references, including representative viruses of the G1 and Y280/G9 lineage, such as A/quail/HongKong/G1/1997, A/chicken/HongKong/G9/1997, and A/HongKong/308/2014. All sera were pretreated and were diluted with PBS to a final dilution fold of 1:10. An equal volume of antigen (8 HAUs/50 $\mu$ l) was added to the sera at a serial 2 fold dilution. The $\mathrm{Hl}$ titers were determined by adding $50 \mu \mathrm{l} /$ well $1 \%$ Turkey RBCs.

\section{Fluorescence-based neuraminidase inhibition assay}

A NA-Fluor ${ }^{\text {TM }}$ Influenza Neuraminidase Assay Kit (Applied Biosystems) was used to test the susceptibility of influenza virus to neuraminidase (NA) inhibitors, zanamivir (kindly provided by GlaxoSmithKline) and oseltamivir carboxylate (kindly provided by Hoffmann-La Roche), as described previously [12]. A/BeijingHaidian/1942/2014 (H3N2) (E119) and A/Texas/12/2007 (H3N2) (E119V) were used as NA inhibitor-sensitive and NA inhibitor-resistant references, respectively. GraphPad Prism 5 software was used to calculate the $\mathrm{IC}_{50}$ (drug concentration required to inhibit NA enzyme activity by $50 \%$ ).

\section{Serological study}

Routine serological surveillance of occupationally exposed populations for avian influenza virus has been implemented since 2008 in mainland China. According to the regulatory policy of the national pandemic preparedness plan in China, informed consent was exempted. Serum samples were collected from poultry workers who are working in live poultry markets, large-scale poultry farms, backyard poultry farms, poultry slaughter factories, or wild bird habitats. Sera were pretreated in 4 volumes of RDE at $37^{\circ} \mathrm{C}$ for 18 hours followed by $56^{\circ} \mathrm{C}$ for 30 minutes. The $\mathrm{HI}$ assay was performed as described in the WHO manual [9]. An $\mathrm{HI}$ titer $\geq 40$ was considered a suspected positive sample, followed by a microneutralization (MN) test for confirmation which was performed as previously described [13]. An MN titer $\geq 40$ was considered seropositive for $\mathrm{H} 9 \mathrm{~N} 2$ infection.

\section{Results}

\section{H9N2 human cases in mainland China}

A total of 33 H9N2-infected human cases were documented from 2013 to 2018 in mainland China. Almost all were mild cases except one fatal case, who suffered from an underlying chronic medical condition. Of the 33 cases, the proportion of males and females was 17:16, and the age ranged from 2 months to 84 years. The median age was 4 years old. Most of the individuals were children under 10 years old (25/33, 75.7\%). The cases were distributed in 9 provinces and one municipality, which were mostly concentrated in central southern China, and two were located in northern China, including Gansu Province and Beijing municipality. Field investigation indicated that 15 of 31 (48.4\%) of the cases had clear poultry exposure histories, whereas 8 of 31 ( $25.8 \%)$ had no poultry exposure histories. Furthermore, the exposure history of $8 / 31$ (25.8\%) cases was unclear. Available viruses and their abbreviation names are listed. In addition to mainland China, the Hong Kong Special Administrative Region (SAR) also reported a total of 8 cases: 2 cases each year in 1999,2009 and 1 case each year in 2003, 2007, 2008 and 2013 [5]. Laboratory-confirmed human H9N2 cases were reported by other countries, such as Bangladesh and Egypt, to the WHO; 2 cases were from Bangladesh, and 4 were from Egypt from 2011 to 2016 [5] (Table1).

\section{Genetic characterization}

A total of 29 human H9N2 virus sequences are available for analysis, including 24 human viruses (2013-2018), one virus (1999) in mainland China, 3 human viruses from Hong Kong and one from Bangladesh. We also chose 4 animal H9N2 viruses and one environment-related G1-like virus for this analysis. E627K and D701N mutations in the PB2 protein were confirmed for the virulence and transmission of H5N1, H7N9 and H9N2 viruses in mammals [14]. We found that 23/29 viruses contained E627 and that 28/29 contained D701. Only A/Sichuan-Bazhou/1453/2014 presented the change E627K. The other 5 Hunan H9N2 isolates, A/Hunan/34179/2018, A/Hunan/42088/2017, A/Hunan/37286/2017, A/Hunan-Chenzhou/45789/2015 and A/Anhui-Lujiang/39/2018, presented E627V substitutions. The E627V mutation has been studied in the H7N9 virus and confirmed to not compromised fitness and transmissibility in both avian and mammalian species [15]. A/Hong Kong/33982/2009 had a D701N substitution.

The amino acid sequence of the HA cleavage site is PSRSSR $\downarrow$ GLF in all tested viruses since 2013, while motifs with more diversity were present in viruses isolated before 2013. All of which indicated molecular markers of low pathogenicity to avian. After 2014, all human H9N2 viruses had acquired Q226L, H183N, A190V and I155T mutations, which were confirmed to be related to human receptor binding preference [16]. Before 2014, human H9N2 viruses contained 2-3 of the 4 abovementioned amino acid site substitutions.

All H9N2 viruses isolated from humans acquired 3 amino acid deletions (positions 63-65) at the NA stalk region after 2013, which were supposed to increase virulence in chickens and mice [17]. NA position 274, 292, 294 and 119 substitutions that supported NA inhibitor resistance were not identified in all human 
H9N2 viruses [18].

The amantadine and rimantadine resistance mutation S31N/G in M2 was present in most H9N2 viruses [19]. Several amino acid changes in internal genes related to increased pathogenicity or virulence in H5N1 avian influenza virus were not identified in H9N2 viruses in this study (Table 2).

\section{Phylogenetic analysis}

All human H9N2 influenza viruses isolated in mainland China in this study belonged to the Y280/G9 lineage. Viruses isolated from 2013 to 2018 were clustered and represented by the viruses A/Hong Kong/308/2014 and A/Anhui-Lujiang/39/2018, candidate vaccine viruses (CVVs). However, $\mathrm{A} /$ Guangdong/333/99 was more similar than the CVVs to previous circulating viruses of the Y280/G9 lineage, such as BJ/94. The NA gene phylogenetic tree of H9N2 viruses showed the same model as the HA gene (Figure 1).

\section{Antigenic analysis}

$\mathrm{HI}$ titers against the homologous viruses ranged from 1:160-1:5120. A one-way $\mathrm{HI}$ assay showed that all the tested human H9N2 influenza viruses reacted well to at least one of the Y280 lineage reference antisera. A/Hong Kong/308/2014 (abbr. HK308) recommended as a vaccine strain in 2014, reacted well with most of the Y280 lineage viruses (12/17) before 2018. However, none of the 5 viruses isolated in 2018 were well inhibited by ferret antisera raised against the reference viruses before 2018. But all the viruses in 2018 reacted well with A/Anhui-Lujiang/39/2018 (abbr. AHLJ39), which was the representative strain in China and was recommended by the WHO as a new candidate vaccine (Table 3 ).

\section{Receptor binding preference}

All tested viruses were able to bind a2,6 sialylglycopolymers, although two viruses, A/Hong Kong/33982/2009 and A/environment/Guangdong/14883/2016, also bound to a2,3 sialylglycopolymers with moderate affinity. These two viruses presented dual receptor binding features. All human infected H9N2 viruses demonstrated the capacity to bind human receptor-like sialylglycopolymers, but different binding profiles existed. Some viruses (3/18), such as HN37286, JX47249 and GD333, had similar high affinities for 6'-SLN and 6'-SL, and some viruses (2/18), such as BJ58064 and GSJYG1397, had a preference for high affinity for 6 '-SLN and lower affinity for 6'-SL. Most viruses (13/18) had a receptor binding preference only for 6'-SLN (Figure 2).

We further tested the binding capacity of the tested H9N2 viruses with different types of erythrocytes (Supplementary Table 1). All viruses presented no hemagglutination with horse erythrocytes, which express almost exclusively a2,3 Gal linkages. Several studies have shown that human, guinea pig, chicken and turkey erythrocytes express both linkages. In addition, chicken erythrocytes display greater SAa2,3 Gal linkages, while turkey erythrocytes display greater SAa2,6 Gal linkages [20]. This is a possible reason why H9N2 virus titers in turkey RBCs were 0-1024-fold higher than those in chicken RBCs in our study.

\section{Antiviral susceptibility of influenza H9N2 viruses}

All 26 tested viruses were fully susceptible to the two NA inhibitors oseltamivir and zanamivir, with mean $\mathrm{IC}_{50}$ values ranging from $0.09-0.78 \mathrm{nM}$. These $\mathrm{IC}_{50}$ values were similar to those of circulating NA inhibitor-susceptible human H3N2 viruses ( $0.1 \mathrm{nM}$ for oseltamivir, $0.45 \mathrm{nM}$ for zanamivir ) The fold change of $\mathrm{H} 9 \mathrm{~N} 2$ viruses $\mathrm{IC}_{50}$ with NA inhibitor- sensitive reference virus's $\mathrm{IC}_{50}$ is less than 4 (Supplementary Table 2).

\section{Seroprevalence of H9N2 viruses in occupationally exposed populations}

Serum samples were collected from occupationally exposed populations from 2015 to 2018 , with $15779,14395,15863$ and 15523 samples, respectively. The seroprevalence rates based on the MN test were 2.15\% (340/15779), 3.17\% (456/14395), 2.93\% (464/15863) and 1.54\% (239/15523) each year. We further compared the positive rate of provinces with H9N2 human case occurrences and of those provinces without H9N2 human case occurrences on a yearly basis. The seroprevalence of provinces with human cases was significantly higher than that of provinces without human cases $(P<0.05)(T a b l e 4)$. We defined a seropositive rate of $2 \%$ as the baseline (average of seropositive rate is $2.4 \%$ ), and the positive rates of 8 provinces in 2015,18 provinces in 2016,15 provinces in 2017 and 8 provinces in 2018 were above the baseline.

\section{Discussion}

H9N2 influenza virus is usually called a panzootic virus since this subtype of virus has been shown to be a donor of internal genes to generate zoonotic influenza viruses with pandemic potential. A prior study revealed that H9N2 influenza virus provided its internal genes to generate a highly pathogenic avian influenza H5N1 virus, which caused the human H5N1 outbreak in Hong Kong in 1997 [21]. Recent studies also supported the understanding of the emergence of novel influenza H7N9, H10N8 and H5N6 viruses from reassortment with six internal genes of circulating H9N2 virus [6-8]. All facts indicated that this subtype of influenza virus had acquired strong abilities of adaptation and spread among the avian population and exhibited high risks to humans after 2013. This situation may have caused human H9N2 influenza cases to be concentrated after 2013.

H9N2 influenza virus has been one of the predominant subtypes affecting poultry health since the end of the twentieth century. It is stably established in chicken flocks and causes endemic outbreaks in vast areas in China. Moreover, this virus can be easily isolated from wild birds, live poultry markets, backyard flocks and the environment in China, even in air samples in live poultry markets [22]. This prevalence is the reason why humans infected by this virus are frequently reported.

The evolution of the H9N2 influenza genotype was comprehensive. Multiple H9N2 genotypes were cocirculating over 10 years before the G57 genotype predominated in vaccinated farm chickens in China. G57 genotype-like viruses finally facilitated the genesis of novel H7N9, H10N8 and H5N6 viruses [23]. Our study showed that recently isolated human H9N2 viruses clustered with G57-like viruses in phylogenetic trees of the HA and NA genes. 
HA of H9N2 influenza viruses continues to evolve into two primary lineages (Y280/G9 and G1), which circulate in the poultry of some countries in Asia and the Middle East, such as China, Vietnam, Egypt and Bangladesh. In mainland China, the Y280/G9 virus has a broad range of hosts, such as chickens, ducks, minor poultry species, swine and humans. However, G1-like viruses have been isolated only from minor poultry and humans in southern China [24]. This result was consistent with our surveillance data of poultry-related environmental samples.

Receptor binding preference has important implications for influenza replication and transmission [25]. Influenza H9N2 viruses have acquired the ability to bind human receptors while circulating in avian species and mammalian hosts. Although this ability was recently demonstrated by most H9N2 viruses, efficient human-to-human transmission was not present. This finding revealed that virus spread among humans needs a more complicated mechanism. Receptor binding preference was also revealed via the hemagglutination phenomenon of H9N2 viruses with different types of erythrocytes.

Clinical signs in chickens with H9N2 virus infection were quite mild. Chickens became more susceptible to secondary infection, especially Escherichia coli infections, with a mortality rate of at least $10 \%$. The virulence of the H9N2 virus was higher in laying hens, and the morbidity of H9N2-infected laying hens was approximately $10 \%$ [26]. Human symptoms induced by the H9N2 virus are analogous to seasonal flu. The outcomes of patients were quick recovery and no lethality. To date, only one fatal case was found in 2016, which occurred in an individual who suffered from a chronic underlying condition. Most human H9N2 influenza cases were found through an influenza-like illness (ILI) surveillance system rather than the unknown pneumonia surveillance system.

Human infection with influenza H9N2 is often unnoticed since it generally results in mild or asymptomatic illness. Serological surveys are an optimal approach to identify subclinical infections and assess the risk of transmission to humans. A number of serological surveys or studies were carried out in some countries of Asia, Africa, the Middle East and North America [27]. Seroprevalence ranged from $1 \%-43 \%$ by $\mathrm{HI}$ and $0.6 \%-9 \%$ by $\mathrm{MN}$, in which the results varied depending upon the infection definition (cut-offs of antibody titer), viruses (circulating or previously circulated), and methods (HI or MN) used for testing. Selection of low titers as cut-offs can lead to overestimation of influenza infection. Cross reaction with circulating seasonal influenza viruses by HI assay usually results in a low sensitivity to influenza infection determination. Few serological studies of influenza H9N2 among the human population, especially for occupationally exposed populations, have been performed in some areas, such as Guangzhou, Jiangsu, Shandong, Beijing, and Shanghai, in China or nationwide [28-30]. These studies were based on designated populations, small sample sizes or short time durations and can reflect a partial view of the infection status of H9N2 influenza in China. Seroprevalence ranged from $0.7-15.5 \%$, which was similar to our study, in which 4-year continual surveillance data were analyzed from 2015 to 2018.

At present, the influenza H9N2 virus has acquired a stronger ability to adapt to avian species and has led to more concern for public health, either directly infecting humans or generating novel influenza viruses with pandemic potential. Serological surveillance also supported that subclinical infection existence. Efforts should be strengthened to monitor virus changes and infection status in terms of providing prepandemic warnings in a timely manner.

\section{Conclusion}

Human influenza H9N2 cases occurred sporadically in China. There no human-to-human transmission has been identified to date. The continuous antigenic drift and human-like receptor binding preference of the H9N2 virus enable it to have a high risk of causing human infections. NA inhibitors are still working as the antiviral against the H9N2 influenza virus. The seropositivity rate in occupationally exposed populations is variable among different regions, implying a substantial threat to public health. We should strengthen the surveillance of human infection with H9N2 influenza virus and the research on virological characteristics.

\section{Abbreviations}

HA: Hemagglutinin

NA: Neuraminidase

NGS: Next generation sequencing

MN: Microneutralization

HI: Hemagglutination inhibition

ILI: Influenza-like illness

CVVs: Candidate vaccine viruses

\section{Declarations}

\section{Ethical Approval and Consent to participate}

Not applicable.

\section{Consent for publication}

Not applicable.

\section{Availability of data and materials}


The datasets used and analyzed during the current study are available from the corresponding author on reasonable request.

\section{Competing interests}

The authors declared that they have no conflicts of interest.

\section{Funding}

This work was supported by the National Key Research and Development Program of China [2018ZX10101002-004-005] and [2018ZX10101002-005-007].

\section{Authors' contributions}

Writing: review and editing: DW. Funding acquisition: LD; JD. Supervision: DW; YS. Conceptualization: DW. Methodology: JD, HB, YZ, LD, WH, SZ, XL, LY, XZ, JL, TC. Writing: original draft preparation: JD. All authors read and approved the final manuscript.

\section{Acknowledgements}

Not applicable.

\section{Authors' information}

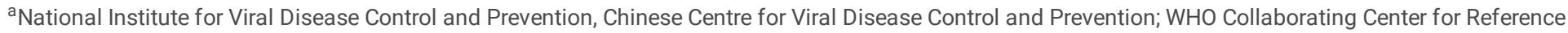
and

Research on Influenza; Key Laboratory for Biosafety, National Health Commission, Beijing, China.

bSchool of Public Health (Shenzhen), Sun Yat-sen University, Guangdong, People's Republic of China.

\section{References}

1. Chen B, Zhang Z, Chen W. The study of avian influenza: I. The isolation and preliminary serological identification of avian influenza virus in chicken. Chin J Vet Med 1994; 20:3-5

2. Guo Y, Li J, Cheng X. Discovery of men infected by avian influenza A (H9N2) virus [in Chinese]. Zhonghua Shi Yan He Lin Chuang Bing Du Xue Za Zhi. 1999;13(2):105-8.

3. Peiris M, Yuen KY, Leung CW, Chan KH, Ip PL, Lai RW, et al. Human infection with influenza H9N2. Lancet. 1999; 354(9182):916-7.

4. Gou Y, Xie J, Wang M. A strain of influenza A H9N2 virus repeatedly isolated from human population in China[in Chinese]. Zhonghua Shi Yan He Lin Chuang Bing Du Xue Za Zhi. 2000;14(3):209-12.

5. World Health Organization. Monthly Risk Assessment Summary. https://www.who.int/influenza/human_animal_interface/HAI_Risk_Assessment/en/. Accessed 27 May 2021.

6. Gao R, Cao B, Hu Y, Feng Z, Wang D, Hu W, et al. Human infection with a novel avian-origin influenza A (H7N9) virus. N Engl J Med. 2013;368(20):1888-97.

7. Chen H, Yuan H, Gao R, Zhang J, Wang D, Xiong Y, et al. Clinical and epidemiological characteristics of a fatal case of avian influenza A H10N8 virus infection: a descriptive study. 2014;383(9918):714-21.

8. Yang L, Zhu W, Li X, Bo H, Zhang Y, Zou S, et al. Genesis and Dissemination of Highly Pathogenic H5N6 Avian Influenza Viruses. J Virol. 2017; 91(5):e02199-16.

9. WHO Group. Manual for the laboratory diagnosis and virological surveillance of influenza. https://apps.who.int/iris/handle/10665/44518. Accessed 27 May 2021.

10. Rutvisuttinunt W, Chinnawirotpisan P, Simasathien S, Shrestha SK, Yoon IK, Klungthong C, et al. Simultaneous and complete genome sequencing of influenza A and B with high coverage by Illumina MiSeq platform. J Virol Methods. 2013;193(2):394-404.

11. Chandrasekaran A, Srinivasan A, Raman R, Viswanathan K, Raguram S, Tumpey TM, et al. Glycan topology determines human adaptation of avian H5N1 virus hemagglutinin. Nat Biotechnol. 2008;26(1):107-13.

12. Huang W, Cheng Y, Li X, Tan M, Wei H, Zhao X, et al. Neuraminidase inhibitor susceptibility profile of human influenza viruses during the 2016-2017 influenza season in Mainland China. J Infect Chemother. 2018;24(9):729-733.

13. Dong L, Bo H, Bai T, Gao R, Dong J, Zhang Y, et al. A combination of serological assays to detect human antibodies to the avian influenza A H7N9 virus. PLoS One. 2014;9(4):e95612.

14. Gabriel G, Dauber B, Wolff T, Planz O, Klenk HD, Stech J. The viral polymerase mediates adaptation of an avian influenza virus to a mammalian host. Proc Natl Acad Sci U S A. 2005;102(51):18590-5.

15. Luk GS, Leung CY, Sia SF, Choy KT, Zhou J, Ho CC, et al. Transmission of H7N9 Influenza Viruses with a Polymorphism at PB2 Residue 627 in Chickens and Ferrets. J Virol. 2015;89(19):9939-51.

16. Li X, Shi J, Guo J, Deng G, Zhang Q, Wang J, et al. Genetics, receptor binding property, and transmissibility in mammals of naturally isolated H9N2 Avian Influenza viruses. PLoS Pathog. 2014;10(11):e1004508. 
17. Sun Y, Tan Y, Wei K, Sun H, Shi Y, Pu J, et al. Amino acid 316 of hemagglutinin and the neuraminidase stalk length influence virulence of H9N2 influenza virus in chickens and mice. J Virol. 2013;87(5):2963-8.

18. Hurt AC, Holien JK, Parker MW, Barr IG. Oseltamivir resistance and the H274Y neuraminidase mutation in seasonal, pandemic and highly pathogenic influenza viruses. Drugs. 2009;69(18):2523-31.

19. Suzuki H, Saito R, Masuda H, Oshitani H, Sato M, Sato I. Emergence of amantadine-resistant influenza A viruses: epidemiological study. J Infect Chemother. 2003;9(3):195-200.

20. Ito T, Suzuki Y, Mitnaul L, Vines A, Kida H, Kawaoka Y. Receptor specificity of influenza A viruses correlates with the agglutination of erythrocytes from different animal species. Virology. 1997;227(2):493-9.

21. Guan Y, Shortridge KF, Krauss S, Webster RG. Molecular characterization of H9N2 influenza viruses: were they the donors of the "internal" genes of H5N1 viruses in Hong Kong? Proc Natl Acad Sci U S A. 1999;96(16):9363-7.

22. Zeng X, Liu M, Zhang H, Wu J, Zhao X, Chen W, et al. Avian influenza H9N2 virus isolated from air samples in LPMs in Jiangxi, China. Virol J. 2017;14(1):136.

23. Pu J, Wang S, Yin Y, Zhang G, Carter RA, Wang J, et al. Evolution of the H9N2 influenza genotype that facilitated the genesis of the novel H7N9 virus. Proc Natl Acad Sci U S A. 2015;112(2):548-53.

24. Xu KM, Li KS, Smith GJ, Li JW, Tai H, Zhang JX, et al. Evolution and molecular epidemiology of H9N2 influenza A viruses from quail in southern China, 2000 to 2005. J Virol. 2007;81(6):2635-45.

25. Vines A, Wells K, Matrosovich M, Castrucci MR, Ito T, Kawaoka Y. The role of influenza A virus hemagglutinin residues 226 and 228 in receptor specificity and host range restriction. J Virol. 1998;72(9):7626-31.

26. Zhang ZJ. The analysis of epidemic diseases in poultry in 2013. China Poultry; 35:56-59. Chinese.

27. Khan SU, Anderson BD, Heil GL, Liang S, Gray GC. A Systematic Review and Meta-Analysis of the Seroprevalence of Influenza A(H9N2) Infection Among Humans. J Infect Dis. 2015;212(4):562-9.

28. Wang M, Fu CX, Zheng BJ. Antibodies against H5 and H9 avian influenza among poultry workers in China. N Engl J Med. 2009;360(24):2583-4.

29. Yu Q, Liu L, Pu J, Zhao J, Sun Y, Shen G, et al. Risk perceptions for avian influenza virus infection among poultry workers, China. Emerg Infect Dis. 2013;19(2):313-6.

30. Li X, Tian B, Jianfang Z, Yongkun C, Xiaodan L, Wenfei Z, et al. A comprehensive retrospective study of the seroprevalence of H9N2 avian influenza viruses in occupationally exposed populations in China. PLoS One. 2017;12(6):e0178328.

\section{Tables}

Table 1. Human-isolated influenza A H9N2 viruses 


\begin{tabular}{|c|c|c|c|c|c|c|c|c|}
\hline No. & Onset time & Province & Sex & Age & Outcome & $\begin{array}{l}\text { Poultry exposure } \\
\text { history }\end{array}$ & Virus isolate & $\begin{array}{l}\text { Virus } \\
\text { abbreviation }\end{array}$ \\
\hline GD-1 & 1998 & Guangdong & Male & $4 y$ & Recovered & Unknown & A/Shantou/217/98 & \\
\hline GD-2 & 1998 & Guangdong & Female & $1 y$ & Recovered & Unknown & A/Shantou/239/98 & \\
\hline GD-3 & 1998 & Guangdong & Female & $36 y$ & Recovered & Yes & A/Shantou/252/98 & \\
\hline GD-4 & 1998 & Guangdong & Male & $14 y$ & Recovered & Yes & A/Shaoguan/402/98 & \\
\hline GD-5 & 1998 & Guangdong & Female & $75 y$ & Recovered & Yes & A/Shaoguan/408/98 & \\
\hline GD-6 & 1999 & Guangdong & Female & $\begin{array}{l}1 \mathrm{y} 10 \\
\mathrm{~m}\end{array}$ & Recovered & None & A/Guangzhou/333/99 & \\
\hline case 1 & 2013.11.19 & Hunan & Male & $7 y$ & Recovered & Yes & $\begin{array}{l}\text { A/Hunan- } \\
\text { Lengshuitan/11197/2013 }\end{array}$ & HNLST11197 \\
\hline case 2 & 2014.12.21 & Guangxi & Male & $35 y$ & Recovered & - & $\begin{array}{l}\text { A/Guangxi- } \\
\text { Jiangzhou/11021/2014 }\end{array}$ & GXJZ11021 \\
\hline case 3 & 2014.12 .5 & Sichuan & Male & $2 y$ & Recovered & - & $\begin{array}{l}\text { A/Sichuan- } \\
\text { Bazhou/1453/2014 }\end{array}$ & SCBZ1453 \\
\hline case 4 & 2014.12.24 & Guangdong & Male & $3 y$ & Recovered & Yes & A/Guangdong/01747/2014 & GD01747 \\
\hline case 5 & 2015.2.4 & Guangdong & Female & $84 y$ & Recovered & Yes & NA & \\
\hline case 6 & 2015.4 .14 & Anhui & Female & $4 y$ & Recovered & Yes & A/Anhui/33329/2015 & АНЗ3329 \\
\hline case 7 & 2015.9 .6 & Anhui & Male & $6 y$ & Recovered & Unknown & A/Anhui/43269/2015 & AH43269 \\
\hline case 8 & 2015.9.1 & Hunan & Male & $2 y$ & Recovered & Unknown & A/Hunan/44558/2015 & HN44558 \\
\hline case 9 & 2015.9 .15 & Hunan & Female & $15 y$ & Recovered & Yes & A/Hunan/44557/2015 & HN44557 \\
\hline case 10 & 2015.10 .27 & Hunan & Female & $1 y$ & Recovered & Unknown & $\begin{array}{l}\text { A/Hunan- } \\
\text { Chenzhou/45789/2015 }\end{array}$ & HNCZ45789 \\
\hline case 11 & 2016.2 .1 & Henan & Female & $5 y$ & Recovered & None & A/Henan/10867/2016 & HeN10867 \\
\hline case 12 & 2016.2 .9 & Sichuan & Female & $57 y$ & Fatal & Unknown & NA & \\
\hline case 13 & 2016.6.10 & Guangdong & Female & $4 y$ & Recovered & Yes & A/Guangdong/SF058/2016 & GDSF058 \\
\hline case 14 & 2016.7 .9 & Guangdong & Male & $\begin{array}{l}2 \mathrm{y} 11 \\
\mathrm{~m}\end{array}$ & Recovered & Yes & $\begin{array}{l}\text { A/Guangdong- } \\
\text { Yuexiu/1822/2016 }\end{array}$ & GDYX1822 \\
\hline case 15 & 2016.8 .2 & Jiangxi & Female & $4 y$ & Recovered & None & A/Jiangxi/47249/2016 & JX47249 \\
\hline case 16 & 2016.8 .7 & Yunnan & Male & $9 \mathrm{~m}$ & Recovered & Yes & NA & \\
\hline case 17 & 2016.8 .8 & Guangdong & Female & 29 & Recovered & Yes & NA & \\
\hline case 18 & 2016.8 .25 & Gansu & Male & $4 y$ & Recovered & None & $\begin{array}{l}\text { A/Gansu- } \\
\text { Jiayuguan/1397/2016 }\end{array}$ & GSJYG1397 \\
\hline case 19 & 2016.12.11 & Beijing & Male & $3 y$ & Recovered & Yes & A/Beijing/58604/2016 & BJ58604 \\
\hline $\begin{array}{l}\text { case } \\
20\end{array}$ & 2016.12.11 & Guangdong & Female & $7 \mathrm{~m}$ & Recovered & Yes & NA & \\
\hline case 21 & 2016.12 .5 & Guangxi & Male & $\begin{array}{l}1 \text { y } 9 \\
\mathrm{~m}\end{array}$ & Recovered & None & NA & \\
\hline case 22 & 2017.2 .6 & Gansu & Male & $11 \mathrm{~m}$ & Recovered & Yes & NA & \\
\hline case 23 & 2017.4 .28 & Beijing & Male & $32 y$ & Recovered & None & NA & \\
\hline case 24 & 2017.4 .28 & Guangdong & Female & $2 \mathrm{~m}$ & Recovered & Unknown & NA & \\
\hline case 25 & 2017.9.18 & Hunan & Male & $9 \mathrm{~m}$ & Recovered & None & A/Hunan/37286/2017 & HN37286 \\
\hline case 26 & $\begin{array}{l}2017.12 . \\
01\end{array}$ & Hunan & Female & $\begin{array}{l}1 \text { y } 8 \\
m\end{array}$ & Recovered & Yes & A/Hunan/42088/2017 & HN42088 \\
\hline case 27 & 2017.12.29 & Anhui & Female & $9 y$ & Recovered & Unknown & A/Anhui-Lujiang/39/2018 & AHLJ39 \\
\hline case 28 & 2018.1.21 & Guangdong & Female & $3 y$ & Recovered & Unknown & A/Guangdong/18SF003/2018 & GD18SF003 \\
\hline case 29 & 2018.2.13 & Beijing & Female & $51 \mathrm{y}$ & Recovered & Yes & NA & \\
\hline case 30 & 2018.7.21 & Guangdong & Female & $24 y$ & Recovered & Unknown & NA & \\
\hline case 31 & 2018.10 .16 & Guangdong & Male & $3 y$ & Recovered & Yes & A/Guangdong/18SF064/2018 & GD18SF064 \\
\hline
\end{tabular}

Page $8 / 13$ 


\begin{tabular}{|c|c|c|c|c|c|c|c|c|}
\hline case 32 & 2018.10 .10 & Guangxi & Male & $3 y$ & Recovered & None & $\begin{array}{l}\text { A/Guangxi- } \\
\text { Xiangshan/11522/2018 }\end{array}$ & GXXS11522 \\
\hline case 33 & 2018.11.27 & Hunan & Male & $2 y$ & Recovered & None & A/Hunan/34179/2018 & HN34179 \\
\hline \multicolumn{9}{|c|}{ Outside mainland China } \\
\hline 1 & 1999 & HK SAR & Female & $13 \mathrm{~m}$ & Recovered & - & & \\
\hline 2 & 1999 & HK SAR & Female & $4 y$ & Recovered & - & & \\
\hline 3 & 2003 & HK SAR & Male & $5 y$ & Recovered & None & & \\
\hline 4 & 2007 & HK SAR & Female & $9 \mathrm{~m}$ & Recovered & Unknown & & \\
\hline 5 & 2008.12 & Shenzhen & Female & $3 \mathrm{~m}$ & Recovered & Yes & & \\
\hline 6 & 2009 & HK SAR & Female & $35 \mathrm{~m}$ & Recovered & - & & \\
\hline 7 & 2009.10 & HKSAR & Female & $47 y$ & Recovered & Unknown & & \\
\hline 8 & 2013.12 .28 & HK SAR & Male & $86 y$ & Recovered & None & & \\
\hline 9 & 2011 & Bangladesh & & & Recovered & - & & \\
\hline 10 & 2015.01.16 & Egypt & Male & $3 y$ & Recovered & Healthy poultry & & \\
\hline 11 & 2015.02 .01 & Bangladesh & Female & $3.5 y$ & Recovered & Poultry & & \\
\hline 12 & 2015.06 & Egypt & Female & $7 y$ & Recovered & Poultry & & \\
\hline 13 & 2015.06 & Egypt & Female & $9 \mathrm{~m}$ & Recovered & Poultry waste & & \\
\hline 14 & 2016.04.10 & Egypt & Male & $18 \mathrm{~m}$ & Recovered & Live poultry market & & \\
\hline
\end{tabular}

Note: - , indicates that information is not available.

Table 2. Key molecular markers of influenza A H9N2 viruses in this study 


\begin{tabular}{|c|c|c|c|c|c|c|c|c|c|c|c|c|c|c|}
\hline \multirow[t]{2}{*}{ Virus } & \multicolumn{5}{|l|}{$\mathrm{HA}$} & \multicolumn{5}{|l|}{ NA } & \multicolumn{2}{|l|}{ M } & \multicolumn{2}{|l|}{ PB2 } \\
\hline & 155 & 183 & 190 & 226 & $\begin{array}{l}\text { HA cleavage } \\
\text { site (333- } \\
341)\end{array}$ & $\begin{array}{l}\text { 63-65 } \\
\text { deletion }\end{array}$ & 274 & 294 & 292 & 119 & 31 & 27 & 627 & 70 \\
\hline A/chicken/Hongkong/G9/1997 & $\mathbf{T}$ & $\mathbf{N}$ & A & $\mathbf{L}$ & PARSSRGLF & NO & $\mathrm{H}$ & $\mathrm{N}$ & $\mathrm{R}$ & $\mathrm{E}$ & S & V & $E$ & $\mathrm{D}$ \\
\hline A/duck/Hongkong/Y280/97 & $\mathrm{T}$ & $\mathbf{N}$ & $\mathrm{T}$ & $\mathrm{L}$ & PARSSRGLF & $\mathbf{Y}$ & $\mathrm{H}$ & $\mathrm{N}$ & $\mathrm{R}$ & $\mathrm{E}$ & & & $\mathrm{E}$ & $\mathrm{D}$ \\
\hline A/guinea fowl/HK/NT101/2003(G1) & $\mathrm{T}$ & $\mathbf{N}$ & A & $\mathbf{L}$ & PARSSRGLF & $\mathbf{Y}$ & $\mathrm{H}$ & $\mathrm{N}$ & $\mathrm{R}$ & $\mathrm{E}$ & S & $\mathrm{V}$ & $\mathrm{E}$ & $\mathrm{D}$ \\
\hline A/Hong Kong/1073/99(G1) & $\mathbf{T}$ & $\mathrm{H}$ & $\mathbf{E}$ & $\mathrm{L}$ & PARSSRGLF & NO & $\mathrm{H}$ & $\mathrm{N}$ & $\mathrm{R}$ & $\mathrm{E}$ & $\mathrm{S}$ & $\mathrm{V}$ & $\mathrm{E}$ & $\mathrm{D}$ \\
\hline A/quail/Hong Kong/G1/97 & $\mathrm{T}$ & $\mathrm{H}$ & $\mathbf{E}$ & $\mathrm{L}$ & PARSSRGLF & NO & $\mathrm{H}$ & $\mathrm{N}$ & $\mathrm{R}$ & $\mathrm{E}$ & S & V & $\mathrm{E}$ & $\mathrm{D}$ \\
\hline A/Bangladesh/0994/2011(G1) & $\mathbf{T}$ & $\mathrm{H}$ & A & L & PAKSSRGLF & NO & $\mathrm{H}$ & $\mathrm{N}$ & $\mathrm{R}$ & $\mathrm{E}$ & $\mathbf{N}$ & V & $\mathrm{E}$ & $\mathrm{D}$ \\
\hline A/Hunan/34179/2018 & $\mathrm{T}$ & $\mathbf{N}$ & $\mathrm{T}$ & $\mathbf{L}$ & PSRSSRGLF & $\mathbf{Y}$ & $\mathrm{H}$ & $\mathrm{N}$ & $\mathrm{R}$ & $\mathrm{E}$ & $\mathbf{N}$ & V & V & $\mathrm{D}$ \\
\hline A/Guangdong/18SF064/2018 & $\mathrm{T}$ & $\mathbf{N}$ & $\mathrm{T}$ & L & PSRSSRGLF & $\mathbf{Y}$ & $\mathrm{H}$ & $\mathrm{N}$ & $\mathrm{R}$ & $\mathrm{E}$ & $\mathbf{N}$ & V & $\mathrm{E}$ & $\mathrm{D}$ \\
\hline A/GXXS/11522/2018 & $\mathrm{T}$ & $\mathbf{N}$ & $\mathrm{T}$ & $\mathrm{L}$ & PSRSSRGLF & $\mathbf{Y}$ & $\mathrm{H}$ & $\mathrm{N}$ & $\mathrm{R}$ & $\mathrm{E}$ & $\mathbf{N}$ & V & $E$ & $\mathrm{D}$ \\
\hline A/AHLJ/39/2018 & $\mathbf{T}$ & $\mathbf{N}$ & $\mathrm{T}$ & $\mathrm{L}$ & PSRSSRGLF & $\mathrm{Y}$ & $\mathrm{H}$ & $\mathrm{N}$ & $\mathrm{R}$ & $\mathrm{E}$ & $\mathbf{N}$ & V & V & $\mathrm{D}$ \\
\hline A/Guangdong/18SF003/2018 & $\mathrm{T}$ & $\mathbf{N}$ & $\mathrm{T}$ & $\mathrm{L}$ & PSRSSRGLF & $\mathbf{Y}$ & $\mathrm{H}$ & $\mathrm{N}$ & $\mathrm{R}$ & $\mathrm{E}$ & $\mathbf{N}$ & $\mathrm{V}$ & $E$ & $\mathrm{D}$ \\
\hline A/Hunan/42088/2017 & $\mathrm{T}$ & $\mathbf{N}$ & $\mathrm{T}$ & $\mathrm{L}$ & PSRSSRGLF & $Y$ & $\mathrm{H}$ & $\mathrm{N}$ & $\mathrm{R}$ & $\mathrm{E}$ & $\mathbf{N}$ & V & V & $\mathrm{D}$ \\
\hline A/Hunan/37286/2017 & $\mathrm{T}$ & $\mathbf{N}$ & $\mathrm{T}$ & L & PSRSSRGLF & $\mathbf{Y}$ & $\mathrm{H}$ & $\mathrm{N}$ & $\mathrm{R}$ & $E$ & $\mathbf{N}$ & $\mathrm{V}$ & V & $\mathrm{D}$ \\
\hline A/Beijing/58604/2016 & $\mathrm{T}$ & $\mathbf{N}$ & $\mathrm{T}$ & $\mathbf{L}$ & PSRSSRGLF & $\mathrm{Y}$ & $\mathrm{H}$ & $\mathrm{N}$ & $\mathrm{R}$ & $E$ & $\mathbf{N}$ & V & $\mathrm{E}$ & $\mathrm{D}$ \\
\hline A/GSJYG/1397/2016 & $\mathrm{T}$ & $\mathbf{N}$ & $\mathrm{T}$ & L & PSRSSRGLF & $\mathbf{Y}$ & $\mathrm{H}$ & $\mathrm{N}$ & $\mathrm{R}$ & $\mathrm{E}$ & $\mathbf{N}$ & $\mathrm{V}$ & $\mathrm{E}$ & $\mathrm{D}$ \\
\hline A/Jiangxi/47249/2016 & $\mathbf{T}$ & $\mathbf{N}$ & $\mathbf{T}$ & $\mathrm{L}$ & PSRSSRGLF & $\mathbf{Y}$ & $\mathrm{H}$ & $\mathrm{N}$ & $\mathrm{R}$ & $E$ & $\mathbf{N}$ & V & $\mathrm{E}$ & $\mathrm{D}$ \\
\hline A/GDYX/1822/2016 & $\mathbf{T}$ & $\mathbf{N}$ & $\mathrm{T}$ & L & PSRSSRGLF & $\mathbf{Y}$ & $\mathrm{H}$ & $\mathrm{N}$ & $\mathrm{R}$ & $\mathrm{E}$ & $\mathbf{N}$ & $\mathrm{V}$ & $\mathrm{E}$ & $\mathrm{D}$ \\
\hline A/Guangdong/SF058/2016 & $\mathrm{T}$ & $\mathbf{N}$ & $\mathrm{T}$ & $\mathrm{L}$ & PSRSSRGLF & $\mathbf{Y}$ & $\mathrm{H}$ & $\mathrm{N}$ & $\mathrm{R}$ & $\mathrm{E}$ & $\mathbf{N}$ & $\mathrm{V}$ & $\mathrm{E}$ & $\mathrm{D}$ \\
\hline A/Henan/10867/2016 & $\mathrm{T}$ & $\mathbf{N}$ & $\mathrm{T}$ & $\mathbf{L}$ & PSRSSRGLF & $\mathrm{Y}$ & $\mathrm{H}$ & $\mathrm{N}$ & $\mathrm{R}$ & $\mathrm{E}$ & $\mathbf{N}$ & $\mathrm{V}$ & $\mathrm{E}$ & $\mathrm{D}$ \\
\hline A/Zhongshan/201501/2015 & $\mathrm{T}$ & $\mathbf{N}$ & $\mathrm{T}$ & $\mathbf{L}$ & PSRSSRGLF & $\mathbf{Y}$ & $\mathrm{H}$ & $\mathrm{N}$ & $\mathrm{R}$ & $\mathrm{E}$ & $\mathbf{N}$ & V & $\mathrm{E}$ & $\mathrm{D}$ \\
\hline A/HNCZ/45789/2015 & $\mathbf{T}$ & $\mathbf{N}$ & $\mathbf{T}$ & $\mathbf{L}$ & PSRSSRGLF & $\mathrm{Y}$ & $\mathrm{H}$ & $\mathrm{N}$ & $\mathrm{R}$ & $\mathrm{E}$ & $\mathbf{N}$ & $\mathrm{V}$ & V & $\mathrm{D}$ \\
\hline A/Hunan/44557/2015 & $\mathbf{T}$ & $\mathbf{N}$ & $\mathrm{T}$ & L & PSRSSRGLF & $\mathbf{Y}$ & $\mathrm{H}$ & $\mathrm{N}$ & $\mathrm{R}$ & $E$ & $\mathbf{N}$ & $\mathrm{v}$ & $\mathrm{E}$ & $\mathrm{D}$ \\
\hline A/Hunan/44558/2015 & $\mathrm{T}$ & $\mathbf{N}$ & $\mathrm{T}$ & $\mathbf{L}$ & PSRSSRGLF & $\mathrm{Y}$ & $\mathrm{H}$ & $\mathrm{N}$ & $\mathrm{R}$ & $\mathrm{E}$ & $\mathbf{N}$ & V & $\mathrm{E}$ & $\mathrm{D}$ \\
\hline A/Anhui/43269/2015 & $\mathrm{T}$ & $\mathbf{N}$ & $\mathrm{T}$ & $\mathrm{L}$ & PSRSSRGLF & $\mathbf{Y}$ & $\mathrm{H}$ & $\mathrm{N}$ & $\mathrm{R}$ & $\mathrm{E}$ & $\mathbf{N}$ & $\mathrm{V}$ & $\mathrm{E}$ & $\mathrm{D}$ \\
\hline A/Anhui/33329/2015 & $\mathrm{T}$ & $\mathbf{N}$ & $\mathrm{T}$ & $\mathbf{L}$ & PSRSSRGLF & $\mathbf{Y}$ & $\mathrm{H}$ & $\mathrm{N}$ & $\mathrm{R}$ & $\mathrm{E}$ & $\mathbf{N}$ & V & $\mathrm{E}$ & $\mathrm{D}$ \\
\hline A/GXJZ/11021/2014 & $\mathrm{T}$ & $\mathbf{N}$ & $\mathrm{T}$ & L & PSRSSRGLF & $\mathrm{Y}$ & $\mathrm{H}$ & $\mathrm{N}$ & $\mathrm{R}$ & $\mathrm{E}$ & $S$ & $\mathrm{~V}$ & $\mathrm{E}$ & $\mathrm{D}$ \\
\hline A/Guangdong/01747/2014 & $\mathrm{T}$ & $\mathbf{N}$ & $\mathrm{T}$ & $\mathbf{L}$ & PSRSSRGLF & $\mathbf{Y}$ & $\mathrm{H}$ & $\mathrm{N}$ & $\mathrm{R}$ & $\mathrm{E}$ & $\mathbf{N}$ & $\mathrm{V}$ & $\mathrm{E}$ & $\mathrm{D}$ \\
\hline A/HNLST/11197/2013 & $\mathbf{T}$ & $\mathbf{N}$ & A & $\mathbf{L}$ & PSRSSRGLF & $\mathrm{Y}$ & $\mathrm{H}$ & $\mathrm{N}$ & $\mathrm{R}$ & $\mathrm{E}$ & $\mathbf{N}$ & V & $\mathrm{E}$ & $\mathrm{D}$ \\
\hline A/SCBZ/1453/2014 & $\mathrm{T}$ & $\mathbf{N}$ & $\mathrm{T}$ & $\mathbf{L}$ & PSRSSRGLF & $\mathrm{Y}$ & $\mathrm{H}$ & $\mathrm{N}$ & $\mathrm{R}$ & $\mathrm{E}$ & $\mathbf{N}$ & $\mathrm{V}$ & $\mathbf{K}$ & $\mathrm{D}$ \\
\hline A/Hongkong/308/2014 & $\mathbf{T}$ & $\mathbf{N}$ & $\mathrm{T}$ & L & PSRSSRGLF & $\mathbf{Y}$ & $\mathrm{H}$ & $\mathrm{N}$ & $\mathrm{R}$ & $\mathrm{E}$ & $\mathbf{N}$ & V & $\mathrm{E}$ & $\mathrm{D}$ \\
\hline A/Hongkong/33982/2009 & $\mathrm{T}$ & $\mathrm{H}$ & D & $\mathrm{Q}$ & PARSNRGLF & NO & $\mathrm{H}$ & $\mathrm{N}$ & $\mathrm{R}$ & $\mathrm{E}$ & & & $\mathrm{E}$ & $\mathbf{N}$ \\
\hline A/Guangdong/333/99 & $\mathrm{T}$ & $\mathbf{N}$ & $\mathrm{T}$ & $\mathrm{L}$ & PSRSSRGLF & NO & $\mathrm{H}$ & $\mathrm{N}$ & $\mathrm{R}$ & $E$ & S & $\mathrm{V}$ & $\mathrm{E}$ & $\mathrm{D}$ \\
\hline A/environment/Guangdong/14883/2016(G1) & $\mathrm{T}$ & $\mathrm{H}$ & A & Q & PARSSRGLF & NO & $\mathrm{H}$ & $\mathrm{N}$ & $\mathrm{R}$ & $E$ & S & $\mathrm{V}$ & $\mathrm{E}$ & $\mathrm{D}$ \\
\hline
\end{tabular}

Table 3. HI titers from antigenic analysis of influenza A H9N2 viruses 


\begin{tabular}{|c|c|c|c|c|c|c|c|c|c|c|c|}
\hline \multirow[t]{2}{*}{ No. } & \multirow{2}{*}{$\begin{array}{l}\text { HA } \\
\text { Clade }\end{array}$} & \multirow[t]{2}{*}{ Reference virus } & \multicolumn{6}{|l|}{ Y280 } & \multicolumn{3}{|c|}{$\mathbf{G 1}$} \\
\hline & & & GD333 & HK-G9 & НКЗ08 & HN11197 & GD01747 & SCBZ1453 & AHLJ39 & $\mathrm{BJ} / 94$ & HK-G1 \\
\hline 1 & Y280 & A/Guangdong/333/99 E6 & 1280 & 640 & $<40$ & 1280 & $<40$ & $<40$ & 80 & 320 & $<40$ \\
\hline 2 & Y280 & A/Chicken/HK/G9/1997 E3 & 320 & $\underline{1280}$ & $<40$ & 640 & $<40$ & $<40$ & 40 & 320 & $<40$ \\
\hline 3 & Y280 & A/HK/308/2014 E5 & $<10$ & 80 & $\underline{5120}$ & 640 & 5120 & 5120 & 640 & $<10$ & $<40$ \\
\hline 4 & Y280 & A/HNLSG/11197/2013 C1E2 & 320 & 640 & 640 & $\underline{5120}$ & 160 & 640 & 320 & 320 & $<40$ \\
\hline 5 & Y280 & A/Guangdong/01747/2014 E2 & $<10$ & 160 & 5120 & 320 & $\underline{5120}$ & 5120 & 1280 & $<10$ & $<40$ \\
\hline 6 & Y280 & A/Sichuan-Bazhou/1453/2014 E2 & $<10$ & 40 & 5120 & 160 & 5120 & $\underline{5120}$ & 5120 & $<10$ & $<40$ \\
\hline 7 & Y280 & A/Anhui-Lujiang/39/2018 & 80 & $<40$ & 640 & 160 & 1280 & 640 & $\underline{5120}$ & ND & ND \\
\hline 8 & $\mathrm{G} 1$ & A/Chicken/BJ/1/1994 E3 & $<10$ & 40 & $<40$ & 160 & $<40$ & $<40$ & $<40$ & $\underline{160}$ & $<40$ \\
\hline \multirow[t]{2}{*}{9} & G1 & A/Quail/Hong Kong/G1/97 E7 & $<10$ & $<40$ & $<40$ & $<40$ & $<40$ & $<40$ & $<40$ & $<10$ & $\underline{1280}$ \\
\hline & & Tested virus & & & & & & & & & \\
\hline 1 & Y280 & A/Hunan/34179/2018 E3 & 80 & 40 & 640 & 160 & 640 & 320 & 1280 & $<20$ & $<40$ \\
\hline 2 & Y280 & A/Guangdong/18SF064/2018 E2 & 80 & $<40$ & 640 & 80 & 640 & 320 & 2560 & $<20$ & $<40$ \\
\hline 3 & Y280 & A/GXXS/11522/2018 C1E2 & 80 & $<40$ & 640 & 160 & 640 & 640 & 2560 & $<20$ & $<40$ \\
\hline 4 & Y280 & A/AHLJ/39/2018 E3 & 80 & $<40$ & 640 & 160 & 1280 & 640 & 5120 & 20 & $<40$ \\
\hline 5 & Y280 & A/Guangdong/18SF003/2018 C1E1 & 80 & $<40$ & 640 & 80 & 640 & 640 & 2560 & 40 & $<40$ \\
\hline 6 & Y280 & A/Hunan/42088/2017 E1 & $<10$ & 80 & 2560 & 320 & 2560 & 2560 & ND & $<10$ & $<40$ \\
\hline 7 & Y280 & A/Hunan/37286/2017 E2 & $<10$ & 80 & 2560 & 640 & 5120 & 5120 & ND & $<10$ & $<40$ \\
\hline 8 & Y280 & A/Beijing/58604/2016 E3 & $<10$ & 80 & 5120 & 160 & 5120 & 5120 & ND & $<10$ & $<40$ \\
\hline 9 & Y280 & A/GSJYG/1397/2016 C2E1 & $<10$ & 80 & 5120 & 320 & 5120 & 5120 & ND & $<10$ & $<40$ \\
\hline 10 & Y280 & A/Jiangxi/47249/2016 E2 & $<10$ & 80 & 2560 & 320 & 2560 & 2560 & ND & $<10$ & $<40$ \\
\hline 11 & Y280 & A/GDYX/1822/2016 C2E2 & $<10$ & 40 & 640 & 640 & 2560 & 2560 & ND & $<10$ & $<40$ \\
\hline 12 & Y280 & A/GD/SF058/2016 E2 & $<10$ & $<40$ & 640 & 320 & 1280 & 640 & ND & $<10$ & $<40$ \\
\hline 13 & Y280 & A/Henan/10867/2016 E2 & $<10$ & $<40$ & 640 & 160 & 2560 & 2560 & ND & $<10$ & $<40$ \\
\hline 14 & Y280 & A/HNCZ/45789/2015 C2E1 & 80 & 320 & 5120 & 640 & 5120 & 5120 & ND & $<10$ & $<40$ \\
\hline 15 & Y280 & A/Hunan/44557/2015 E2 & $<10$ & 40 & 1280 & 160 & 1280 & 1280 & ND & $<10$ & $<40$ \\
\hline 16 & Y280 & A/Hunan/44558/2015 E3 & $<10$ & 40 & 2560 & 320 & 5120 & 5120 & ND & $<10$ & $<40$ \\
\hline 17 & Y280 & A/Anhui/43269/2015 E2 & $<10$ & 40 & 1280 & 160 & 2560 & 2560 & ND & $<10$ & $<40$ \\
\hline 18 & Y280 & A/Anhui/33329/2015 E2 & $<10$ & $<40$ & 640 & 640 & 2560 & 2560 & ND & $<10$ & 40 \\
\hline 19 & Y280 & A/GXJZ/11021/2014 E3 & $<10$ & 80 & 5120 & 320 & 5120 & 5120 & ND & $<10$ & $<40$ \\
\hline 20 & Y280 & A/GD/01747/2014 E3 & $<10$ & 40 & 5120 & 320 & 5120 & 5120 & ND & $<10$ & $<40$ \\
\hline 21 & Y280 & A/SCBZ/1453/2014 E3 & $<10$ & 80 & 5120 & 320 & 5120 & 5120 & ND & $<10$ & $<40$ \\
\hline 22 & Y280 & A/HNLSG/11197/2013 C1E2 & 320 & 640 & 640 & 5120 & 160 & 640 & 320 & 320 & $<40$ \\
\hline 23 & $\mathrm{G} 1$ & $\mathrm{~A} / \mathrm{HK} / 33982 / 2009$ V1E5 & $<10$ & $<40$ & $<40$ & $<40$ & $<40$ & $<40$ & ND & $<10$ & 320 \\
\hline 24 & $\mathrm{G} 1$ & A/Environment/GD/14883/2016 E2 & $<10$ & $<40$ & $<40$ & $<40$ & $<40$ & $<40$ & ND & 40 & 80 \\
\hline
\end{tabular}

Note:_ indicates $\mathrm{HI}$ titers against the homologous viruses

Red letters indicate the $\mathrm{HI}$ titers $>4$ fold difference with the $\mathrm{HI}$ titers against the homologous viruses

ND indicates not done

Table 4. Comparison of influenza H9N2 seroprevalence between provinces with and without human cases 


\begin{tabular}{|c|c|c|c|c|c|c|}
\hline \multirow[t]{2}{*}{ Year } & \multicolumn{2}{|c|}{$\begin{array}{l}\text { Provinces with } \\
\text { human cases }\end{array}$} & \multicolumn{2}{|c|}{ Provinces without human cases } & \multirow[t]{2}{*}{$x^{2}$} & \multirow[t]{2}{*}{$\mathrm{P}$} \\
\hline & positive & negative & positive & negative & & \\
\hline 2015 & 117 & 3837 & 223 & 11602 & 16.187 & $P<0.05$ \\
\hline 2016 & 146 & 3435 & 310 & 10504 & 12.849 & $\mathrm{P}<0.05$ \\
\hline 2017 & 137 & 2561 & 327 & 12838 & 53.06 & $P<0.05$ \\
\hline 2018 & 68 & 2966 & 171 & 12318 & 12.246 & $\mathrm{P}<0.05$ \\
\hline
\end{tabular}

\section{Figures}

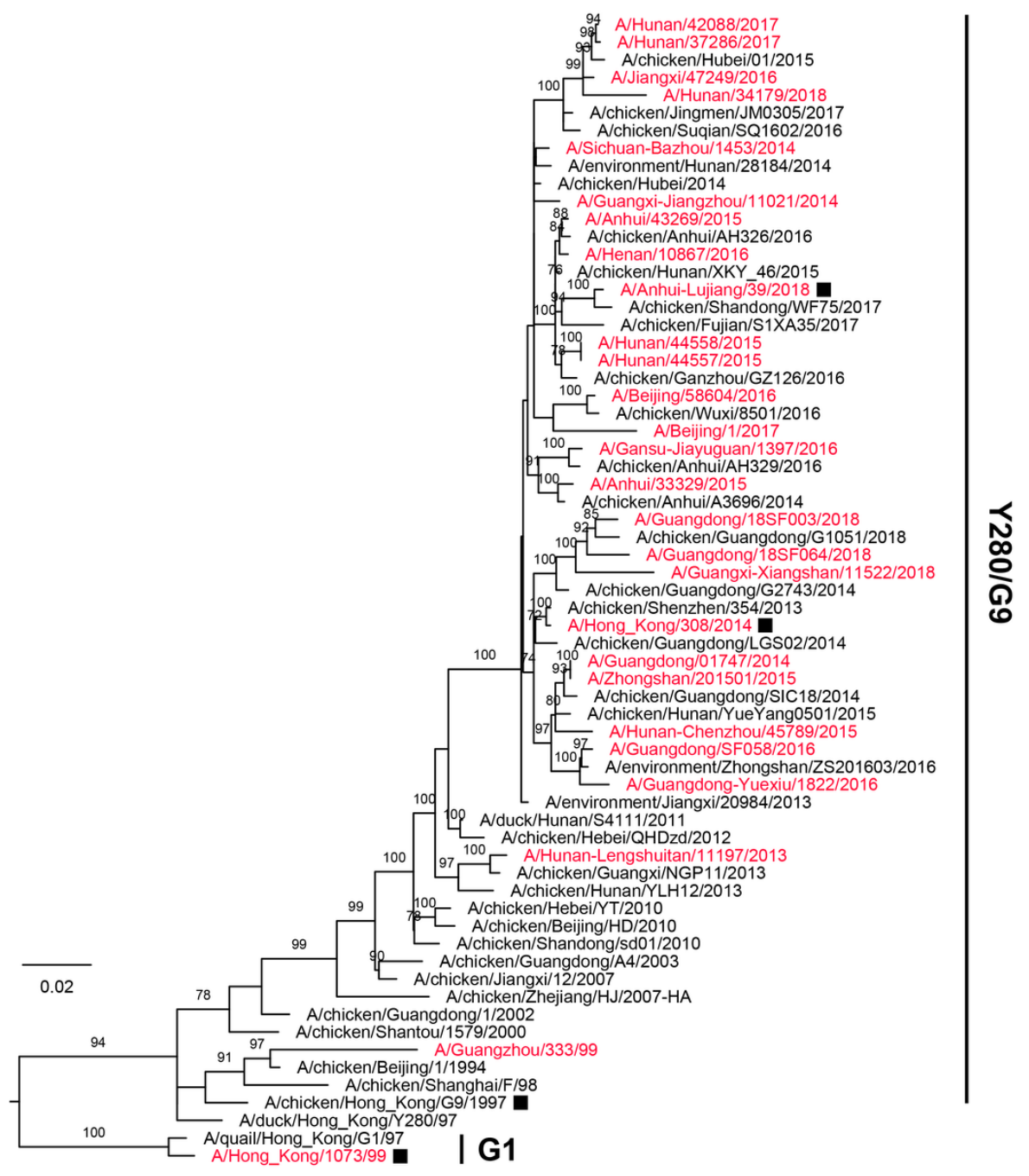

Figure 1

Phylogenetic trees of HA and NA genes from influenza A H9N2 viruses. Phylogenetic tree was constructed using the Maximum Likelihood method in MEGA 6.06. The bootstrap value was tested with 1000 replications. Viruses in black square indicated being selected as the human H9N2 vaccine candidate recommended by WHO. 

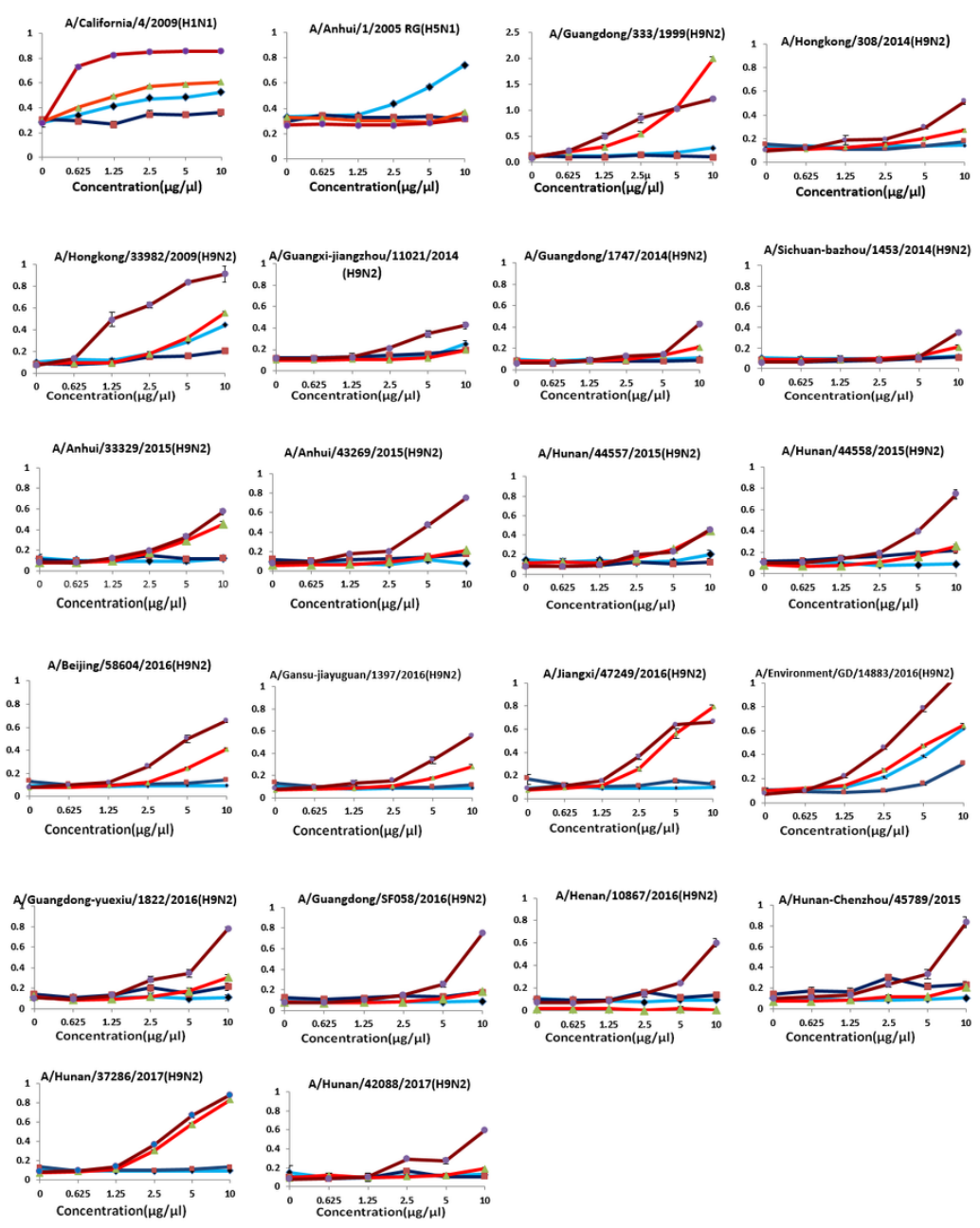

$\rightarrow-02,3 \cdot 5 L \rightarrow-02,3 \cdot 5 L \mathrm{LLN} \rightarrow-02,6 \cdot 5 \mathrm{LL} \rightarrow-\alpha 2,6 \cdot 5 \mathrm{SLN}$

\section{Figure 2}

Receptor binding properties of Influenza A H9N2 viruses. Horizontal coordinates: glycans concentration, Vertical coordinates: Absorbance 450nm®Binding affinity of the viruses to four different biotinylated glycans ( 6'-SLN , 3'-SLN and 6'-SL, 3'-SL). 6'-SLN and 6'-SL were used to represent as a2,6- linked sialic acid, 3'-SLN and 3'-SL were used to represent as a2,3- linked sialic acid. glycans at the concentration of $0,0.3125,0.625,1.25,2.5 \mathrm{and} 5 \mu \mathrm{g} / \mathrm{ml}$. The data shown were the means of two separate assays performed induplicate and absorbance was read at $450 \mathrm{~nm}$. The pandemic H1N1 virus (A/California/04/2009) and H5N1 virus (A/Anhui/01/2005 RG) were used as a2,6 and a2,3 receptor binding control.'

\section{Supplementary Files}

This is a list of supplementary files associated with this preprint. Click to download.

- SupplementaryTable1.docx

- SupplementaryTable2.docx 